\title{
Decoding actions and emotions in deaf children: Evidence from a biological motion task
}

\author{
Amanda Katherine Ludlow ${ }^{\mathrm{a}}$, Pamela Heaton ${ }^{\mathrm{b}}$ \& Christine Deruelle ${ }^{\mathrm{c}}$ \\ a University of Birmingham, United Kingdom \\ b Goldsmiths College, University of London, United Kingdom \\ c Institut de Neurosciences de la Timone, Centre National de Recherche Scientifique, France
}

\begin{abstract}
This study aimed to explore the recognition of emotional and non-emotional biological movements in children with severe and profound deafness. 24 deaf children, together with 24 control children matched on mental age and 24 control children matched on chronological age, were asked to identify a person's actions, subjective states, emotions, and objects conveyed by moving point-light displays. Results showed that when observing point light displays, deaf children showed impairments across all conditions (emotions, actions and moving objects) compared to their chronological age matched controls but showed no differences across subjective states. The results are supportive that deaf children present developmental delays in their biological motion apart from the ones relative to their own mental state, and that this may be interpreted in relation to the expertise they have acquired in decoding action toward themselves. The findings are discussed in relation to deaf children viewing motion stimuli very differently to hearing children (e.g. Bosworth \& Dobkins, 2002).
\end{abstract}

Deficits in emotional and social interactions have been widely reported in deaf children (Kusché, Garfield, \& Greenberg, 1983; Vernon \& Greenberg, 1999; Wauters \& Knoors, 2007, Weisel \& Bar-Lev, 1992). Since the development of linguistic skills and socio-emotional competences have been closely linked (e.g., Malle, 2002), these deficits have been consistently attributed to delays in language acquisition and/or reduced opportunities to converse about personal experiences with other people (e.g., Peterson \& Siegal, 1995; 1998).

Among the social impairments documented in deaf populations are problems in understanding other people's emotions (e.g., Rieffe \& Terwogt, 2000). These difficulties have often been interpreted as Theory of Mind (ToM) deficits, thereby implicating a lack of awareness of other people's mental states. Deficits in ToM abilities have been most commonly reported in congenitally deaf children of hearing parents who have not been exposed to sign language (Peterson \& Siegal, 1995, 1998, Remmel \& Peters, 2008, Russell et al., 1998, Steeds, Rowe \& Dowker, 1997) suggesting an early and specific need for interactions with a native speaker. Indeed deficits in ToM abilities have also been observed in late-signing deaf children (Peterson \& Slaughter, 2006). Given that the ability to understand emotions is related to measures of social competence (Custrini \& Feldman, 1989), ratings of peer popularity and likeability (Denham, McKinley, Couchoud, \& Holt, 1990), and academic achievement scores (Nowicki \& Duke, 1992), questions about the ways that deaf children access emotion information are important.

Experimental studies into social abilities in deaf populations have emphasized delays in understanding other people's emotions (e.g., Dyck, Farrugia, Shochet \& Holmes-Brown, 2004). However to date, studies testing facially expressed emotions in the deaf have produced equivocal findings. Early studies indicated that deaf children do make more errors in recognising facial expressions of emotion than hearing children and deficits are greater in those with pre-lingual than post-lingual hearing loss (Bachara, Raphael \& Phelan, 1980; Schiff, 1973). However, in later studies where deaf and hearing children were presented with simple emotion recognition tasks that involved emotion matching, group differences did not emerge (Hosie, Gray, Russell, Scott \& Hunter, 1998).

It is noteworthy that the majority of research studies that have addressed questions about emotion recognition abilities in deaf populations have relied on photographic, thus static, representations of facial expressions (e.g., Dyck et al., 2004). However dynamic faces have been argued to give a more accurate measure of performance as it is similar to what we experience in everyday life whereas static faces may underestimate a person's ability to recognise emotions (Moore, 2001). The motion in dynamic faces provides independent information about emotional expression that is not available in posed static faces (Hill \& Johnston, 2001) and research has shown that recognition and discrimination of emotions is superior in dynamic compared to static displays (e.g., Bould \& Morris, 2008; Werhle et al., 2000).

Whilst it is clear that expressions of emotion are powerfully conveyed by faces, movement of body parts are also important as both context and gestures provide vital sources from which we derive emotional meanings (e.g., Clarke, Bradshaw, Field, Hampson, \& Rose, 2005; Pollick, Hill, Calder, \& Paterson, 2003). For example, when point-lights are attached to the joints of an invisible moving human in a dark room, the visual system can rapidly and reliably distinguish these from similar motion patterns that do not emanate from human beings (e.g., Johansson, 1973). Indeed, a number of studies have shown that complex information, such as emotions, desires, intentions, and dispositions, expressed by a single person or mutual agents can be reliably conveyed using point light cues (Blake \& Shiffrar, 2007; Chouchourelou, Toshihiko, Harber \& Shiffrar, 2006; Clarke, Bradshaw, Field, Hampson \& Rose, 2005). Whilst sensitivity to point-light displays substantially increases during the first 5 years of life 
(Pavlova, Kragelch-Mann, Sokolov \& Birbaumer, 2001), evidence suggests that such abilities are visible at the earliest stages in perceptual development (e.g., Bertenthal \& Pinto, 1994) and may be implicated in the development of non-verbal social communication skills (Dittrich, Troscianko, Lea, Morgan, 1996).

For individuals who are deaf or hard of hearing, recognition of emotional expression from body gesture would appear to be vital. However, relatively little is known about the extent to which deaf children utilize such cues. One recent strand of research has provided evidence that deaf children adopt alternative perceptual strategies to hearing children. For example, they rely more heavily on motion cues whilst gauging when to cross a busy road (Bosworth \& Dobkins, 2002) and when comprehending critical linguistic information in the hand movements of British sign language (Corina et al., 2007). It is surprising, given both the importance of motion for emotion understanding, and findings suggesting atypical motion processing in deaf children, that motion processing in communication domains has not been widely studied in this population.

Evidence supporting the benefit of using motion cues to improve understanding of socio-emotional content has been investigated in other clinical populations, including autism spectrum disorders (ASD). This work has built on earlier findings showing deficits in ToM and emotional face-processing (e.g., Celani, Battacchi \& Arcidiacono, 1999). The study, carried out by Parron et al. (2008) investigated action and emotion interpretation using point light displays (PLD) in children with ASD. These findings revealed a dissociation with impaired performance relative to age and intelligence matched controls on PLDs with emotional value, but no impairment relative to controls, on PLDs depicting simple personal actions, subjective states and objects. These findings were consistent with previous studies showing a selective impairment in interpreting PLDs with emotional content in autism (Hubert et al., 2007; Moore, Hobson \& Lee, 1997).

As previous studies into emotion recognition in deaf children have largely utilised static representations of faces, the nature of the emotion processing deficit is currently unclear. In order to capitalize on their proven strengths in motion processing (Bosworth \& Dobkins, 2002; Corina et al., 2007), we adopted the methods used by Parron et al. (2008) and used PLDs to test the assumption of a global emotion-processing deficit in deaf children. Point lights techniques have been used previously with deaf populations to assess how sign language influences action processing (Knapp, Cho \& Corina, 2008). In Knapp et al., study, adult deaf signers and hearing non-signers were asked to detect signed and pantomimic point-light movements that were embedded in a field of white noise dots. Whilst the hearing non-signers found it harder to detect differences in sign movements than in pantomimic movements, deaf subjects showed a similar pattern of performance across the two conditions. This difference suggests that deaf participants - compared to hearing participants — do not differentiate signs from other nonlinguistic gestures.

In the current study, children with severe or profound hearing difficulties, and hearing controls were tested on their ability to recognize a person's actions, subjective states, emotions, and objects conveyed by moving point-light displays. The study aimed to ascertain whether children with severe or profound hearing loss recognize basic human actions represented by PLDs and to determine whether discrimination performance is influenced by the emotional content of the displays.

\section{Method}

\section{Participants}

Participants were 24 children with severe or profound bilateral, congenital deafness. The sample included 10 boys and 14 girls, aged between 6 years 8 months and 16 years and 10 months (mean age $=13$ years 3 months, SD = 3 years 1 month). All of these participants attended mainstream schools with units specializing in the education of hearing impaired children. Of these 24 children, eleven were profoundly deaf (hearing loss $>90 \mathrm{db}$ ) and 13 were severely deaf (hearing loss $>70 \mathrm{db}$ ). None had known associated medical disorders at the time of testing and visual examination was found to be normal. Neuropsychological evaluation was conducted by means of the Standard Progressive Raven Matrices (Raven, Raven \& Court, 1992) (range 67-123, mean score = 83.1, SD = 14.8). Mental age scores (mean mental age $=9$ years 3 months, $\mathrm{SD}=2$ years 4 months) were derived from scores on the Standard Progressive Raven Matrices. The children were matched on non-verbal ability as deaf children are thought to rely more heavily on nonverbal cues in the development of emotions. Further justification for matching children using scores derived from the Raven Matrices, is provided by Albanese et al., (2010) who found nonverbal intelligence to exert an effect on improving children's emotion understanding.

Two groups of typically developing children also participated in the study. The children were recruited via state schools and class teachers, who assisted in participant recruitment, were asked to nominate children of average intellectual ability. None of these children had overt physical handicap, learning difficulties or known neurological/psychiatric deficits and all had normal to corrected vision and normal audition. The 24 children in the first comparison group were individually matched to the children in the deaf group for gender and mental age scores (MA-matched, aged from 4 years 3 months to 13 years 4 months: mean chronological age $=9$ years 5 months, $\mathrm{SD}=2$ years 1 month). In addition to gender, the 24 children in the second comparison group were individually matched to the children in the deaf group for chronological age (CA-matched, aged from 6 years 4 months to 17 years, mean chronological age $=12$ years 5 months, $\mathrm{SD}=2$ years 4 months). This matching procedure has been adopted in a number of published studies using PLDs (e.g., Parron et al., 2008; Hubert et al., 2007) and allows interpretation of results in terms of developmental delay and/or developmental deviance. By comparing with a CA-match group, any individual differences found in deaf children would suggest developmental delay. In contrast, if deaf children are found to be different than both MA and CA then this difference can be accounted for by atypical deviance in that behavior (Hodapp, Burack \& Zigler, 1990; Leonard, 1998). 


\section{Materials}

Tasks and stimuli were chosen to replicate the procedures initially used in Moore et al. (1997, Experiments 2 and 3 ) and further replicated in both Hubert et al., 2007 and Parron et al., 2008). Stimuli were video clips each of 5 seconds duration. They showed dynamic point-lights displays of a male actor performing 14 actions. There were also a further 5 control stimuli of manipulated PLDs of everyday objects: a ball rotating, a pair of kitchen balance scales moving as a weight was added, an ironing board being opened and closed, a dustpan and brush sweeping, and a saw in action. In each case 10 reflective point lights were distributed across the object in a manner that meant the object was not recognizable from a still image. There were also five clips of the actor displaying subjective states - actions that reflect an underlying state such as itchiness or tiredness - and five clips of the actor depicting emotional actions - happy, angry etc. (complete list of the video clips is given in Table 1). By using the same stimuli used in previous research, it allowed us to be able to compare our results, stimuli without any emotion compared to those with emotional valence (emotion, subjective states) reflexive versus non reflexive. The action condition is larger to reflect that the action repertoire is thought to be much bigger than both the emotional and the subjective state ones.

Table 1: The Point Light Display sequences.

\begin{tabular}{cc}
\hline CONDITION & $\begin{array}{c}\text { Lifting/hopping/kicking/jumping (both, right foot, left } \\
\text { foot/pushing/digging }\end{array}$ \\
Action & $\begin{array}{c}\text { Sitting/Climbing/Running/Clapping/shooting a ball/ } \\
\text { Itchy/Bored/Tired/Cold/Hurt }\end{array}$ \\
$\begin{array}{c}\text { Subjective States } \\
\text { Emotional States } \\
\text { Object }\end{array}$ & $\begin{array}{c}\text { Surprised/Sad/Frightened/Angry/Happy } \\
\text { Ball rotating/Kitchen scales moving as weights added/Iron board } \\
\text { opened up and closed/Dust pan and brush sweeping/Saw in action. }\end{array}$ \\
\hline
\end{tabular}

\section{Procedure}

Participants were individually tested, in a quiet classroom located in the school or day care centre. They were seated in front of a computer screen at a viewing distance of $60 \mathrm{~cm}$. Participants were asked to watch the movies and to describe what was happening. Participants were told that they were going to be presented with short movies and that they were going to be asked to communicate orally or through sign what they had seen. All responses were recorded by the experimenter who was an experienced signer (although not fluent). However a teaching assistant fluent in sign was also present during these sessions to ensure that the children understood the tasks and that the children's responses were reported correctly. Responses were scored as correct when participants accurately captured the object, the action, the state or the emotion portrayed by the PLDs or provided a sign that approximated the action or state. It is important to note that responses were also considered as correct when participant provided a synonymous word that indicated the object, the action, the state or the emotion captured by the PLDs. In the emotion condition, responses were scored as correct if they captured the emotional experience. Each participant completed a total of 29 trials: 14 in the Action condition) 5 in the Subjective states condition, 5 in the Emotional states condition, and 5 in the Object condition. The order of trials presentation was randomized for each subject.

\section{Results}

\section{Performance accuracy across conditions}

A 3 x 4 ANOVA with Group (Deaf, MA-matched, CA-matched) as a between-subjects factor and Condition (actions, subjective states, emotions, objects) as a within-subjects factor was conducted using the mean accuracy rates as the dependent variable. This analysis revealed a main effect of Group, $\mathrm{F}(2,69)=5.19, \mathrm{MSE}=.90, \mathrm{p}<.01, \eta^{2}=.13$. Tukey Post-hoc analyses indicated that deaf participants produced significantly more errors than CA-matched (mean difference $=.43$, $\mathrm{p}<.01$ ) but no difference compared to MA-matched participants (mean difference $=.26, p=.14$ ) and there was no difference in accuracy between MA- and CA-matched participants (mean difference $=0.18, \mathrm{p}=.41$ ). Means and standard deviations for the different experimental conditions are shown in Table 2.

Table 2: Mean Accuracy (\%) and SD (in italic) across the four conditions

\begin{tabular}{lllll}
\hline & Action & Emotion & Subjective & Objects \\
\cline { 2 - 6 } Deaf & $64.8(11.7)$ & $50.00(18.7)$ & $60(26.4)$ & $14.2(19.1)$ \\
CA & $80.6(11.9)$ & $64.2(33.8)$ & $65.8(21.7)$ & $40(24.3)$ \\
MA & $73.5(18.9)$ & $58.3(33.8)$ & $55.8(29.5)$ & $39.2(30.9)$ \\
\hline
\end{tabular}

This analysis also showed a main effect of Condition, $\mathrm{F}(3,207)=48.76$, MSE $=.31$, $\mathrm{p}<.001$, $\eta^{2}=.41$, with better performance in the action compared to the other three conditions (Emotion: mean difference $=.31$, $p<.001$; Subjective state: mean difference $=.237, \mathrm{p}<.005$; Object: mean difference $=1.059, \mathrm{p}<.001)$. There was no difference in accuracy between the emotion and the subjective state conditions (mean difference $=.073, \mathrm{p}=.46$ ) but there were fewer errors in the emotion and subjective states compared to the object condition (respectively, mean difference $=.75, \mathrm{p}<.001$, mean difference $=.82, \mathrm{p}<.001$ ) 
Importantly, there was a significant group by condition interaction $\left(F(6,207)=.2 .53, \mathrm{MSE}=.31, \mathrm{p}<.05, \eta^{2}=.07\right)$. The interaction was analyzed using post-hoc Tukey tests. These analyses revealed that for the action condition the deaf group obtained significantly lower scores than CA-matched controls (mean difference $=.40, \mathrm{p}<.001$ ) and the MA-matched controls (mean difference $=.22, \mathrm{p}<.05)$. On the object condition they were significantly less accurate than both the CA- (mean difference $=.74$, $\mathrm{p}<.001$ ) and the MA-matched controls (mean difference $=.75, \mathrm{p}<.001$ ). For the emotion condition they were marginally less accurate than the CA matched controls (mean difference $=.47, \mathrm{p}=.05$ ), but not the MA-matched controls (mean difference $=.16$, $\mathrm{p}=.51$ ). Finally, the deaf participants scores on the subjective condition did not differ from those of the CA (mean difference $=$ $.15, \mathrm{p}=.48$ ) or the MA-matched controls (mean difference $=.07, \mathrm{p}=.75$ ).

Because of the marginal difference in the emotion condition and the apparent large difference in the standard deviations between the groups, a Levene's test (Tabacknick \& Fidell, 2001) for homogeneity of variances was performed. Due to a violation in the homogeneity of variance, a correction for the degrees of freedom was applied for the four types of stimuli. Results revealed that for the action condition, deaf children's scores were significantly lower than those of CA and MA children ( $\mathrm{t}(42.21)=4.6, \mathrm{p}$ $<.001$ and $\mathrm{t}(36.58)=2.14, \mathrm{p}<.05$, respectively). On the emotion condition, deaf children were significantly less accurate than $\mathrm{CA},(\mathrm{t}(30.25)=2.18, \mathrm{p}<.05)$, but not MA matched children, $(\mathrm{t}(30.47)=.74, \mathrm{p}<.47)$. Deaf children's scores were significantly lower on the objects condition than CA, $(\mathrm{t}(45.84)=3.93, \mathrm{p}<.001)$, and MA matched children, $(\mathrm{t}(43)=3.49$, $\mathrm{p}<.001)$. Finally, for the subjective states, the results revealed no significant differences between deaf and CA or MA groups $(\mathrm{t}(43.90)=.77, \mathrm{p}=$ .45 and $\mathrm{t}(45.40)=.30, \mathrm{p}=.77)$, respectively. Importantly, the scores for the CA and MA control groups did not differ across any of the conditions: action (mean difference $=.18, \mathrm{p}=.20$ ), emotion (mean difference $=.31, \mathrm{p}=.39$ ), subjective $($ mean difference $=$ $.21, \mathrm{p}=.56)$ and object (mean difference $=.003, \mathrm{p}=.99$ ).

\section{Effect of age on performance levels}

To evaluate the contribution of age to accuracy across the four motion conditions, hierarchical multiple regressions were carried out separately between the deaf and their mental age matched controls and another between the deaf children and their chronological age matched controls. Each of the motion conditions was used as a dependent variable with age and group (deaf and MA/deaf and CA) as the independent variables. An age x group interaction was entered as a second step in to the regression. The groups were coded (Deaf $=0$ and $C A=1$ ) in the first regression and (Deaf $=0$ and $M A=1$ ) in the second one. The standard regression coefficients are shown in Table 3.

Table 3: Standard Regression Coefficients

\begin{tabular}{|c|c|c|c|c|c|c|}
\hline \multirow[b]{3}{*}{ Action } & \multicolumn{3}{|c|}{ Deaf and Chronological Age } & \multicolumn{3}{|c|}{ Deaf and Mental Age } \\
\hline & Age & Group & Age x Group & Age & Group & Age x Group \\
\hline & $.37 * * *$ & $.49 * * *$ & -.09 & $.58 * * *$ & $.47 * * *$ & $.93 *$ \\
\hline Emotion & .03 & .25 & .51 & $.43 * *$ & $.31 *$ & $2.02 * * *$ \\
\hline Subjective & .17 & .09 & .33 & $.35^{*}$ & .043 & .95 \\
\hline Object & .18 & $.48 * * *$ & -.002 & $.43 * * *$ & $.59 * * *$ & $1.07 *$ \\
\hline
\end{tabular}

The results revealed that for the deaf and CA, only performance for action was predicted by increasing age. Performance on both the action and object conditions was predicted by group with the deaf performing comparatively poorer than the CA across both conditions.

Importantly for the deaf children and MA, age predicted performance in all conditions with the children showing better performance with increasing age. Group also predicted performance for each of the conditions, except for the subjective condition. Deaf children were poorer than MA across each of the other three conditions. There were also significant interactions between age and group in all but the subjective conditions, showing that age had a different pattern on performance in the deaf children compared to the MA controls. Further regression analyses revealed that in the action condition, age significantly predicted performance in the MA $(\beta=.67, p<.001)$ and the deaf $(\beta=-.51, p<.05)$. However whilst in MA group, the older the children the better their performance, this effect was reversed for the deaf group whereby the older children got progressively poorer in the action condition. In the object condition, age significantly predicted performance in the MA $(\beta=.63$, p <.001) but this effect was not found for the deaf children $(\beta=.27, \mathrm{p}=.21)$. The same pattern was shown in the emotion condition, age significantly predicted performance in the MA $(\beta=.79, p<.001)$ but this effect was not found for the deaf children $(\beta=-.07, p=.74)$. Thus age appears to have a more powerful effect upon performance in the MA group compared to the deaf group. Therefore, regardless of the inclusion of a much younger age MA control group, these children performed better than their older deaf counterparts. Thus, when controlling for intelligence, clear differences are observed across deaf and hearing children with the deaf consistently poorer on the biological motion task.

\section{Degree of hearing loss and signing ability}

In order to further uncover factors implicated in successful task performance in the deaf participants, we carried out further analyses (ANOVA). The first of these showed that there was no effect of severity of hearing loss on error rate, $(\mathrm{F}(1,23)=.10, \mathrm{p}=$ .75). As research has shown that deaf children with signing family members perform as well as age and intelligence matched hearing children on emotion recognition and theory of mind tasks (Courtin, 2000; Peterson \& Siegal, 1999); we compared the 
total numbers of correct scores, obtained by the twelve deaf children who had signing family members (aged 6 years 9 months-15 years 8 months: mean $=10$ years 3 months, $\mathrm{SD}=3.4$ ) with those obtained by the twelve children without signing family members (aged 6 years 8 months-16 years 10 months: mean $=12$ years 4 months, SD $=2.4$ ). This included 7 families where only the mother signed and 4 where both parents signed. 5 out of the 12 families were learning BSL level 1 and the remaining 8 had completed BSL level 3. Only one child has non hearing parents and in this case both the mother and father were profoundly deaf. The analysis failed to show any significant differences $(F(2,23)=.51, p=.61)$. We then compared scores for the thirteen deaf children who preferred to communicate using sign language (aged 6 years 8 months-15 years 8 months: mean = 10 years 2 months, $\mathrm{SD}=3.20$ ) with those of the eleven deaf children who preferred to communicate orally (aged 7 years 8 months-16 years 10 months: mean $=12$ years 8 months, $\mathrm{SD}=2.53)$. Again, this comparison did not reveal any significant difference $(\mathrm{F}(1,23)=$ $.21, \mathrm{p}=.65) .1$

\section{Discussion}

The findings from the study showed that whilst deaf and hearing children matched for mental and chronological age did not differ in their ability to identify subjective states from point light displays, identification of emotions, actions and objects were significantly impaired in the deaf group. In comparison to the MA-matched control group their performance scores on the object and action condition were significantly lower and in comparison with their CA-matched control group their scores were significantly lower across emotions, actions and objects conditions. Therefore, deaf children were poorer across most of the experimental conditions, providing additional support that deaf children may actually view motion stimuli very differently to hearing children (e.g. Bosworth \& Dobkins, 2002). Deaf children differ from hearing children in detecting visual cues for objects and actions as well as their ability to decode subtle visual cues for emotions.

This difference in levels of performance across experimental conditions in the deaf group did not simply reflect changes in levels of difficulty across conditions. Consistent with findings from earlier studies (Hubert et al., 2007; Parron et al., 2008) our results from the hearing controls showed that children's performance was poorest on the object condition whilst performing best on the action condition. Whilst the deaf participants showed the same pattern, their scores were nevertheless poorer than those of controls especially in the action condition.

Performance of the deaf children across the emotion condition was consistent with previous research showing that deaf children exhibit difficulties in emotion recognition (e.g., Dyck, Farrugia, Shochet \& Holmes-Brown, 2004). The deaf children showed poorer performance across the emotion conditions compared to CA. However the findings fail to support our hypothesis speculating that motion may significantly enhance emotion identification ability in the deaf (e.g. Hill \& Johnston, 2001). Static representations (e.g. photographs) of emotional stimuli provide relatively impoverished information about social situations. Indeed, work carried out with hearing populations, have observed increased recognition of emotions when test stimuli are dynamic (Bould \& Morris, 2008) and yet this was not observed in the deaf group.

Problems in understanding other people's emotions (e.g., Rieffe \& Terwogt, 2000) have often been interpreted in the context of lack of Theory of Mind. Findings from studies testing these mentalizing abilities in deaf participants have reported deficits (e.g., Rieffe \& Terwogt, 2000), and these may provide evidence for a deficit at the social cognitive level (Tager-Flusberg \& Sullivan, 2000). However whilst the results found the deaf children to identify fewer emotions from the point light displays, no differences were found across subjective states between the deaf children and the two control groups. This double dissociation between emotions and subjective emotions may reflect deaf childrens' ability to have a better understanding of their own emotions but a specific difficulty in the understanding of the emotions of others. For example, Rieffe \& Terwogt (2000) found when looking at spontaneous use of mental states in explaining other people's emotions, that 6 and 10 year old deaf children's references to desires exceeded their hearing peers and were even found to increase with age. One interpretation of better self awareness is that the deaf children may concentrate on the expression and understanding of their own desires in order to make effective use of their interaction time to ensure that others unambiguously understand their wants. Therefore, understanding one's own emotion appears to remain intact in deaf children.

An unresolved but important question is whether the deaf children scored at a lower level across the biological motion task compared to their matched controls due to their deafness per se, such that their auditory deprivation is responsible for motion deficits through limited ability to communicate with others (e.g., Peterson \& Siegal, 1995, 1998), or whether experience with sign language played a role. A limitation to the current study is that all deaf children were signers, and there was found to be no differences between the deaf children who favored communicating orally compared to those who favored sign. Therefore, these results cannot be interpreted in terms of whether level of signing ability in deaf children affects the ability to decode emotional and non-emotional content. In the deaf literature key differences have often been observed in children exposed to sign from birth (e.g. Emmorey \& McCullough, 2009) but only one child in the present study was a native signer, thus preventing further conclusions to be drawn on the experience of sign. Future studies need to address both native signers and hearing signers in order to unravel this question.

1 A post-hoc power analysis using G*Power (Erdfelder, Faul, \& Buchner, 1996), revealed a small to medium size effect (.37) using the conventions proposed by Cohen (1977). Analysis also revealed that the probability of finding this power $(1-\beta)=$ .97 . 
Another important question is how the four motion conditions relate to each other. Pelphrey, Adolphs and Morris (2004) have suggested that different aspects of social perception are subserved by different, specialized brain systems and that perception of bodily motion relies on one such specialized system. Frith and Frith (1999) have further suggested that the ability to mentalise may have evolved from a system for representing actions in the brain. For example the Mirror Neuron System (MNS) is hypothesised to be a perception-action matching system that is automatically engaged during the observation of both communicative and non-communicative gestures and actions. In addition, areas outside the MNS such as the superior temporal sulcus (STS) are also involved in the perception of biological motion and more broadly in processing social communication (e.g., Grossman et al., 2002). Visual regions including the fusiform face area (FFA) and the extrastriate body area (EBA) are also recruited during the perception of gestures and actions involving the hands, arms and face (Mortgomery \& Haxby, 2008).

Importantly, linguistic articulators for sign language are the same as those involved in everyday human actions, such as reaching, grasping, object manipulation and communicative gesture. Different experiences with manual communication might then alter the nature of the neural systems that underlie action for deaf signers (Corina et al., 2007) and thus differences in any system representing actions may lead to problems in social perception including Theory of Mind. Whilst problems in understanding other people's emotions have often been attributed directly to deaf children's lack of opportunity to converse it is possible that this may in fact be more specific to children signing experience. This then implies that experience using a visual language shifts neural processing of human actions (Corina, \& Knapp, (2008); Knapp, Cho, \& Corina, (2008); Knapp, \& Corina, (2010).

Given that neural mechanisms specialized for the perception of biological activity appear to play an important role in social perception (Allison, Puce \& McCarthy, 2000; Wheaton, Pipinges, Siberstein \& Puce, 2001) studies using biological motion paradigms will be important in enabling researchers to address outstanding questions about the role of action perception in deaf individuals. Whilst deafness alone is thought to enhance certain aspects of an individual's visual attention (see Bavelier, Dye \& Hauser, 2006), specifically deafness causes an individual to allocate more attention to the visual periphery and be more sensitive to motion on the periphery, effects of competency in a visual language may also enhance some cognitive functions (Emmorey \& Kosslyn, 1996).

\section{References}

Albanesea, O., De Stasiob, S., Di Chiacchioc, C., Fiorillia, C., \& Ponsd, F. (2010). Emotion Comprehension: The Impact of Nonverbal Intelligence. The Journal of Genetic Psychology: Research and Theory on Human Development, 171(2), 101 -115 .

Allison, T., Puce, A., \& McCarthy, G. (2000). Social perception from visual cues: role of the STS region. Trends in Cognitive Science, 4, 267-278.

Bachara, G. H., Raphael, J., \& Phelan, W. J. (1980). Empathy development in deaf preadolescents. American Annals of the Deaf, $125,38-41$.

Bavelier, D., Dye, M. W., Hauser, P. C. (2006). Do deaf individuals see better? Trends in Cognitive Science, 10(11), $512-518$.

Bertenthal, B. I., \& Pinto, J. (1994). Global processing of biological motions. Psychological Science, 5, 221-225.

Blake, R., \& Shiffrar, M. (2007). Perception of human motion. Annual Review of Psychology, 58, 47-73.

Bould, E., \& Morris, N. (2008). Role of motion signals in recognizing subtle facial expressions of emotion. British Journal of Psychology, 99, 167-189.

Bosworth, R. G., \& Dobkins, K.R. (2002). Visual Field Asymmetries for Motion Processing in Deaf and Hearing Signers. Brain and Cognition 49, 170-181.

Celani, G., Battacchi, M. W. \& Arcidiacono, L. (1999). The understanding of the emotional meaning of facial expressions in people with autism. Journal of Autism and Developmental Disorders, 29, 57-66.

Chouchourelou, A., Toshihiko, M., Harber, K., \& Shiffrar, M. (2006). The visual analysis of emotional actions. Social Neuroscience, 1, 63-74.

Clarke, T. J., Bradshaw, M. F., Field, D. T., Hampson, S. E., \& Rose, D. (2005). The perception of emotion from body movement in point-light displays of interpersonal dialogue. Perception, 34, 1171-1180.

Cohen, J. (1977). Statistical Power Analysis for the Behavioural Sciences. New York: Academic Press.

Courtin, C. (2000). The impact of sign language on cognitive development of deaf children: The case of theories of mind. Journal of Deaf Studies and Deaf Education, 5(3), 266-276.

Corina, D. P., Chiu, Y., Knapp, H., Greenwald, R., Jose-Robertson, L., \& Braun, A., (2007). Neural correlates of human action observation in hearing and deaf subjects. Brain Research, 1152(4), 111-129.

Corina, D. P., \& Knapp, H. P. (2008). Signed Language and Human Action Processing: Evidence for Functional Constraints on the Human Mirror-Neuron System. Annals New York Academy Sciences, 1145, 100-112. 
Custrini, R.J., \& Feldman, R.S. (1989). Children's understanding of emotional facial expressions and decoding of emotions. Journal of Child Clinical Psychology, 18, 336-342.

Denham, S.A., McKinley, M., Couchoud, E.A., \& Holt, R. (1990). Emotional and behavioral predictors of preschool peer ratings. Child Development, 61, 1145-1152.

Dittrich, W.H., Troscianko, T., Lea, S.E., \& Morgan, D. (1996). Perception of emotion from dynamic point-light displays represented in dance. Perception, 25(6), 727-38.

Dyck, M.J., Farrugia, C., Shochet, I. M., \& Holmes-Brown, M. (2004). Emotion recognition/understanding ability in hearing or vision-impaired children: do sounds sights, or words make the difference? Journal of Child Psychology and Psychiatry, 45(5), 789-800.

Emmorey, K., \& Kosslyn, S.M. (1996). Enhanced Image Generation Abilities in Deaf Signers: A Right Hemisphere Effect. Brain and Cognition, 32, 28-44.

Emmorey, K., \& McCullough, S. (2009). The bimodal brain: Effects of sign language experience. Brain and Language, 110(2), 208-21

Erdfelder, E., Faul, F. \& Buchner, A. (1996). GPOWER: A general power analysis program. Behavior Research Methods, Instruments, \& Computers, 28, 1-11.

Frith, C.D., \& Frith, U. (1999). Interacting minds- A biological basis. Cognitive Psychology, 286, 1692-1695.

Grossman, E. D., \& Blake, R. (2002). Brain areas active during visual perception of biological motion. Neuron, 35, 1167-1175.

Hill, H., \& Johnston, A. (2001). Categorizing sex and identity from the biological motion of faces. Current Biology, 11, 880- 885.

Hodapp, R. M., Burack, J. A., \& Zigler, E. (Eds.). (1990). Issues in the developmental approach to mental retardation. New York: Cambridge University Press.

Hosie, J., Gray, C., Russell, P., Scott, C., \& Hunter, N. (1998). The matching of facial expressions by deaf and hearing children and their production and comprehension of emotion labels. Motivation and Emotion, 22, 293-313.

Hubert, B., Wicker, B., Moore, D. G., Monfardini, E., Duverger, H., Da Fonseca, D., \& Deruelle, C. (2007). Brief report: recognition of emotional and non-emotional biological motion in individuals with autistic spectrum disorders. Journal of Autism and Developmental Disorders, 37(7), 1386-1392.

Johansson, G. (1973). Visual perception of biological motion and a model for its analysis. Perception and Psychophysics, 14, 201-211.

Knapp, H. P., Cho, H., \& Corina, D. P. (2008). Perception of sign language and human actions. In M. R. de Quadros (Ed.), TISLR 9: Theoretical Issues in Sign Language Research 9. Congreso International de Aspectos Teóricos das Pesquisas nas Linguas de Sinais. December 6 to 9, 2006 Universidade Federal de Santa Catarina Floriano'́polis, SC Brasil. Floriano' polis: Lagoa Editora (2006).

Knapp, H. P., \& Corina, D.P. (2010). A human mirror neuron system for language: Perspectives from signed languages of the deaf. Brain and Language, 112, 36-43.

Kusché, C. A., Garfield, T. S., \& Greenberg, M.T. (1983). The understanding of emotional and social attributions in deaf adolescents. Journal of Clinical Child Psychology, 12, 153-160.

Leonard, L. B. (1998). Children with specific language impairment. Cambridge, MA: MIT Press.

Malle, B. F. (2002). Verbs of interpersonal causality and the folk theory of mind and behavior. In M. Shibatani (Ed.), The grammar of causation and interpersonal manipulation (pp. 57-83). Amsterdam: Benjamins.

Montgomery, K. J., Haxby J. V. (2008). Mirror neuron system differentially activated by facial expressions and social hand gestures: a functional magnetic resonance imaging study. Journal of Cogniyive Neuroscience,20, 1866--1877.

Moore, D. G., Hobson, R. \& Lee. A. (1997). Components of person perception: An investigation with autistic, non-autistic retarded and typically developing children and adolescents. British Journal of Developmental Psychology, 15, 401-423.

Moore, D. G. (2001). Reassessing emotion recognition performance in people with mental retardation: A review. American Journal of Mental Retardation, 106, 481-502.

Nowicki, S., \& Duke, M.P. (1992). The association of children's nonverbal decoding abilities with their popularity, locus of control, and academic achievement. The Journal of Genetic Psychology, 153, 385-393.

Parron, C., Da Fonseca, D., Santos, A., Moore, D.G., Monfardini, E., \& Deruelle, C. (2008). Recognition of biological motion in children with autistic spectrum disorders. Autism,12(3), 261-274.

Pavlova, M., Krageloh-Mann, I., Sokolov, A., \& Birbaumer, N. (2001). Recognition of point-light biological motion displays by 
young children. Perception, 30, 925 - 933.

Pelphrey, K., Adolphs, R., \& Morris, J. P. (2004). Neuroanatomical substrates of social cognition dysfunction in autism. Mental Retardation Developmental Disabilities Research Review, 10(4), 259-271.

Peterson. C., \& Siegal, M. (1995). Deafness, conversation and theory of mind. Journal of Child Psychology and Psychiatry, $36,459-474$.

Peterson, C., \& Siegal, M. (1998). Changing focus on the representational mind. Deaf, autistic and normal hearing children's concepts of false photos, false drawings and false beliefs. British Journal of Developmental Psychology, 16, 301-320.

Peterson, C. \& Slaughter, V. (2006). Telling the story of ToM: Deaf and hearing children's narratives and false belief understanding. British Journal of Developmental Psychology, 24, 151-179.

Pollick, F. E., Hill, H., Calder, A. \& Paterson, H. (2003). Recognizing facial expression from spatially and temporally modified movements. Perception, 32(2), 813-826.

Raven, J. C., Court, J. H. \& Raven, J. (1992). The Standard Progressive Matrices. Oxford: Oxford University Press.

Remmel, E., \& Peters, K. (2008). Theory of mind and language in children with cochlear implants. Journal of Deaf Studies and Deaf Education, 14(2), 218-36.

Rieffe, C., \& Terwogt, M. (2000). Deaf children's understanding of emotions: Desires take precedence. Journal of Child Psychology and Psychiatry, 41, 601-608.

Russell, J. A., Hosie, C. D., Gray, C., Scott, C., Hunter, N., Banks, J. S., \& Macaualy, M. C. (1998). The development of the ory of mind in deaf children. Journal of Child Psychology and Psychiatry, 39, 903-910.

Schiff, W. (1973). Social-event perception and stimulus pooling in deaf and hearing observers. American Journal of Psychology, $86,61-78$.

Steeds, L., Rowe, K., \& Dowler, A. (1997). Deaf children's understanding of beliefs and desires. Journal of Deaf Studies and Deaf Education, 2, 185-195.

Tabachnick, B.G., \& Fidell, L.S. (2001). Using Multivariate Statistics. Allyn and Bacon: London

Tager-Flusberg, H., \& Sullivan, K. (2000). A componential view of theory of mind: evidence from Williams syndrome. Cognition, 76, 59-89.

Vernon, M., \& Greenberg, S. (1999). Violence in deaf and hard-of-hearing people: A review of the literature. Aggression and Violent Behaviour, 4, 259-272.

Wauters, L.N. \& Knoors, H. (2007). Social integration of deaf children in inclusive settings. Journal of Deaf Studies and Deaf Education, 13(1), 21-36.

Weisel, A., \& Bar-Lev, H. (1992). Role taking ability, nonverbal sensitivity, language and social adjustment of deaf adolescents. Educational Psychology, 12(1), 3-13.

Wehrle, T., Kaiser, S., Schmidt, S., \& Scherer, K.R. (2000). Studying the dynamics of emotional expression using synthesized facial muscle movements. Journal of Personality and Social Psychology,78, 105-119.

Wheaton, K., Pipingas, A., Silberstein, R., \& Puce, A., (2001). Neuronal responses elicited to viewing the actions of others. Vision Neuroscience, 18, 401-406. 